\title{
Der kleine Hobbit - Roboter in der Pflege
}

— Mehr Unabhängigkeit im Alter - das ist künftig auch mit technischer Assistenz möglich. Zukunftsvisionen in der Pflege werden am 23. Januar auf dem Kongress Pflege 2016 vorgestellt: Ein Roboter, der erkennt, ob der Bewohner gestürzt ist, einen Notruf absetzen kann, Essen aus der Küche bringt oder an Termine erinnert. Ein solcher Heimassistent ist keine Zukunftsmusik mehr - „Hobbit" wurde 2015 in 18 Haushalten in Österreich, Schweden und Griechenland getestet. „Viele Senioren sind an technischen Assistenten interessiert", stellt Dr. Tobias Körtner, Projektmanager des EU-Projekts an der Akademie für Altersforschung am Haus der Barmherzigkeit in

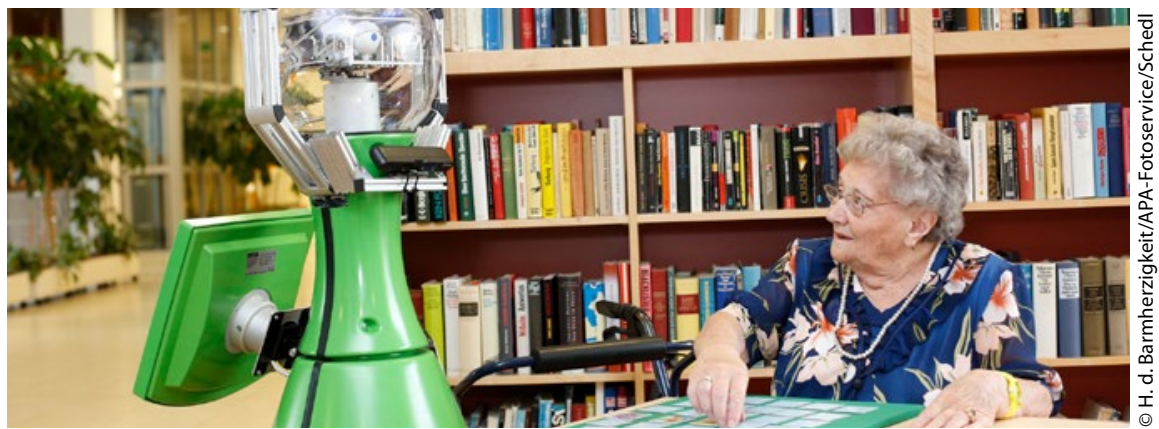

Diabetes im Alter

\section{Herausforderungen in Heim und Klinik}

_ Ein Viertel aller Diabetiker ist älter als 75 Jahre. Deshalb werden immer mehr Menschen mit der Nebendiagnose Diabetes in Langzeitpflegeeinrichtungen und Kliniken betreut. Pflegekräfte in den Einrichtungen müssen daher die besonderen Risiken dieser Patienten berücksichtigen. So sind ältere diabetologische Patienten durch hohe Infektanfälligkeit und die damit verbundene eingeschränkte Wundheilung sehr verletztlich. Auf dem Kongress Pflege 2016 zeigen Experten Lösungswege auf - sei es für die
Versorgung von Patienten mit diabetischem Fußsyndrom oder hinsichtlich der parenteralen Ernährung bei Diabetes mellitus. Vorgestellt werden aber auch die neue Weiterbildungssäule Diabetes-Pflege der Deutschen Diabetes Gesellschaft, DDG, sowie die Erfahrungen eines zertifizierten DiabetesSchwerpunktpflegedienstes. Der erste zertifizierte Pflegedienst ging im Oktober 2014 an den Start.

Termin: 23.1.2016, $13.30-15.30 \mathrm{Uhr}$
Wien, fest. "Und die Aufgeschlossenheit wird zunehmen", ist er sich sicher. Ziel sei es, dass Senioren mit Hilfe solcher Serviceroboter länger in der Selbstständigkeit leben können. Die Wissenschaftler an der Akademie für Altersforschung tüfteln außerdem am Roboter "Henry", ein internationaler Forschungsroboter, der bereits im Wiener Haus der Barmherzigkeit seine Runden drehte. Weltweit wird an Pflegerobotern gebastelt, die bewegungseingeschränkte Menschen heben, die Hol- und Bringdienste erledigen, Medikamente heraussuchen und transportieren können. „Doch bis solche technische Assistenten routinemäßig im Einsatz sind, wird es noch viele Jahre dauern", betont Körtner.

Termin: 23. Januar 2016, 13.30 - 16.00 Uhr.

\section{KTQ-Zertifizierung Leuchturmprojekt}

— Der Nachweis eines internen Qualitätsmanagement ist für Gesundheitseinrichtungen Pflichtprogramm. Seit 15 Jahren steht das $\mathrm{KTQ}^{\circledR}$-Verfahren für Transparenz und Qualität im Gesundheitswesen. Was wurde in der Zwischenzeit erreicht? Wie sieht heute ein verschlanktes Zertifizierungsverfahren aus? Und vor allem: Welchen Mehrwert hat die $\mathrm{KTQ}^{\oplus}$-Zertifizierung für die Pflege? Fragen, die in der Pflegepraxis und im Pflegemanagement immer wieder gestellt und in Rahmen eines Workshops aufgegriffen werden. So unterstützt das Zertifizierungsverfahren Lösungen zur Verbesserung der Mitarbeiter- und Patientenorientierung. Erfahrungen aus dem Klinikalltag vermitteln die Städtischen Kliniken Mönchengladbach als "Leuchturm“ der $\mathrm{KTQ}^{\oplus}$-zertifizierten Einrichtungen.

Termin: 22.1.2016, 17.00 - 19.00 Uhr
Informationen und

Buchungen unter:

www.gesundheitskongress.de 